$25^{\text {th }}$ International Conference on Coastal Engineering, Orlando, Fl, 1996

\title{
EDUCATION OF COASTAL ENGINEERS FOR THE 50th ICCE
}

\author{
Henk Jan Verhagen ${ }^{1}$
}

\section{INTRODUCTION}

In general the problem in education is that we teach nowadays students the knowledge from five years ago, to be applied in the next 5 to 15 years (I admit, the student of today will have reached his retirement when he will participate in the 50th ICCE, the title is exaggerating reality). When one analyses the developments in the profession, it is clear that teaching present day facts is not very useful. We have to teach approaches, designphilosophy, concepts, etc. What the meaning is for education of coastal engineers will be worked out in this paper.

\section{CHANGES}

In the past engineers only had to look at the technical aspects. Nowadays, the impact on society and environment, the costs and the sustainability are at least as important. The consequence of this is that the role of coastal engineers has changed considerably in the past few years. Recently a joint IAHR-UNESCO panel addressed the current developments in hydraulic engineering and their implications for the education of hydraulic engineers [KOBUS $E T A L ., 1994]$. Being specialized hydraulic engineers, many of the conclusions of this panel are also valid for Coastal Engineers. With reference to the UNCED '92, the panel concluded that "hydraulic engineering should be taught in a broad context of the natural and social environment and must enhance the engineer's sense of responsibility for sustainable water development within environmental and societal limitations."

Fortunately, also the tools for the engineers have changed considerably. In the past much was done based on experience, engineering judgement and empirical formula. Verification was usually only possible by means of measuring in prototype or by physical modelling. Worldwide research in coastal sciences and coastal engineering has shown the following two developments:

- a considerable increase in the domain knowledge (knowledge of coastal processes);

- advanced tools have been developed like mathematical models (in various dimensions) and decision support systems. For design and project development the role of the

Associate professor in coastal engineering, Int. Inst. for Infrastructural, Hydraulic and Environmental Engineering (IHE-Delft), P.O. Box 3015, 2601 DA Delft, The Netherlands 
physical models is almost completely taken over by the mathematical models.

A general trend can be observed from applying rules to more conceptual thinking. Rules will change fast, so it is more important for an engineer to know the design philosophy. Also engineers have to learn where to find the most up-to-date knowledge regarding the design which he is making at a certain moment. Because the increased growth in science, rules are outdated faster than in the past; this means that in most cases engineers should not apply the rules they have learned in university. So they should be trained always first to verify if the design method they learned in university is still valid.

Engineers should be trained in a flexible application of the design methodologies they have learned.

For design purposes the use of complicated computer software is increasing. The packages become more and more user friendly, but the insight in the computational process becomes less. This means that the direct link between output and input is less obvious. Engineers have to become more and more aware of the need of checking the output of these programs in inconsistencies (rather than on numerical accuracy). Because of the high quality of presentation methods of modern software, input inconsistencies are often not recognised in time. Engineers have to be trained to become more and more keen on this problem.

\section{TYPES OF ENGINEERS}

Because of this development one may distinguish nowadays three types of coastal engineers:

- the research-engineers, involved in expanding the understanding of the coastal processes; using advanced analysis of field data and sophisticated physical models;

- the "toolmakers", engineers involved in translating the newly gained knowledge into mathematical models and encapsulate this knowledge in various knowledge based systems (Hydroinformatics, see ABBOTT [1994]);

- the design engineers (the tool-users), contributing in solving the coastal problems in a multi-disciplinary team.

The first two types of engineers produce products which can be used globally. Results from research done in Australia can easily be used in Iceland. Also (the better) tools can be used anywhere. Tools, developed in the Netherlands can easily be used in Sri Lanka. However, applying the tools for solving local problems requires the specific local knowledge of the various parameters of the system. In his keynote speech to Copedec IV, professor Hildebrando [HILDEBRANDO, 1995] gave an overview of the labour market for coastal engineers (based on Brazilian experiences), and he came to the conclusion that the demand for coastal engineers will grow in the following main fields of activities: Design, Construction, Operation and Research. He came also to the conclusion that the demand for researchers is relatively limited, compared to the other fields.

\section{WHAT IS A (COASTAL) ENGINEER ?}

An engineer is a trained person, able to solve practical problems in society (and in our case of course related to the coast), using technical means. In this paper I focus on the engineer with an academic education. From such an engineer it is expected that he is able to solve problems which cannot be solved by applying standard handbook solutions. Therefore he has to be able to understand the problem (analyze the cause of the problem), find in a creative way a path towards a solution of the problem, and implement that solution (make a "construction", however in this sense a "construction" is not necessarily concrete and steel, 
it may also be a beach nourishment or the implementation of a set-back system). Usually this process is called "design".

An important point is that the academically trained engineer has to bear "design responsibility". This means that he is responsible for the effect of the construction on the human and non-human environment. This includes of course the aimed effects (an erosion protection should protect against erosion), but also not non-aimed effects (an erosion protection should not increase downstream erosion without consultation with the downstream coastal manager).

So the main objective of the engineer is to solve the problem, only understanding is not sufficient. Understanding is only an intermediate step.

At this moment the process description in our profession is in many cases weaker than in other engineering professions. Many formulas used in coastal engineering are empirical or have important empirical coefficients (examples are the sediment transport formulas and the formulas for the stability of armour units). Apart from this, we usually have to work with considerably unreliable input data (e.g. wave data, waterlevels). And last but not least, the materials used in coastal engineering (rock) have a highly variable strength. The result of this all is that the main art of coastal engineering is the handling of uncertainties.

Because uncertainties are so important (and even will become more important in the future), a coastal engineer should have a good knowledge of statistics and probabilistic methods. In many engineering professions uncertainties can be handled by using a "safetycoefficient" or the use of a characteristic value (like the $95 \%$ value used in concrete engineering). However, because of the wide standard deviations in the distributions of the parameters common in coastal engineering, often only a full probabilistic approach leads towards acceptable solutions.

In coastal engineering the "client" is often the government. Especially when considering coastal protection works (notably beach nourishments), the link between the paying organisation and the beneficiaries are sometimes unclear. This makes that financing coastal protection works is sometimes quite difficult and prone to an other form of uncertainties.

\section{SCIENCE AND ENGINEERING}

This also shows the main difference between a scientist and an engineer. The objective of a scientist is to understand the world. For a coastal scientist it means understanding the coastal processes. Sometimes this understanding is expressed in models. Some scientists think they understand a system when they are able to model the system (usually with mathematical descriptions). Personally I think models can help to understand the process, but the fact that you are able to model a process does not necessarily means that you understand the system. The aim of a scientis is to make this understanding as complete as possible. Also an engineer needs understanding, otherwise he is not able to solve any problem. But his research will be focused towards the needed solution of the problem, not towards a full understanding of the process.

An important point to mention is the worldwide focus on the "pure science" in coastal engineering. Much research in coastal engineering leads to longer formulas, not to better applicable formulas, as is proclaimed by SMITH [1994]. Reviewing most journals on coastal engineering, he came to the conclusion that only very few papers were focusing on 
engineering, while most papers were focused on coastal science.

\section{TRAINING}

At most universities emphasis is put on the study of various coastal sciences for increasing our knowledge of the coastal processes. This is very important work, that has to be continued; however the consequence is that most students are only trained for this kind of research, and much less for practical engineering. So, in fact, we are mainly training the first 2 types of engineers, and neglecting the type 3 (the design engineer). Therefore it is necessary that apart from the education of coastal researchers attention is also paid to the education of engineers, i.e. people who are able to solve practical problems and design solutions.

When one analyzes "problem coasts", in most cases the coastal engineer is confronted with several types of problems. Among others, the following types can be distinguished:

- the "obvious" mistake;

- lack of data (no accurate boundary conditions);

- no accurate design method available.

The most usual problem is the "obvious" mistake. For example, buildings constructed too near to the waterline at an eroding coastline, undesirable effects of downstream erosion due to coastal works, etc. In these cases the origin of the problem is not really an engineering problem, but absence of awareness of coastal behaviour at (political) decision making level. It is more a political problem than a technical problem. A better technical training of engineers will never solve this kind of problems, one has to create coastal awareness at the group of clients. This requires communicative skills and the ability to compose clear and understandable reports. Usually this is a weak point of technical people, therefore special attention has to be paid to this point in the education of engineers.

Also very often no detailed input data are available for making an appropriate design. Accurate long-term wave data are very scarce. This means for an engineer:

- he has to learn how to "generate" data (hindcasting, combining several sources of data, etc.)

- he has to learn to make the design in such a way that the influence of unreliable input data is as minimal as possible (for example using probabilistic methods).

In order to solve the third kind of problem (no design method available to the designer), he first has to find out, if such a design method exists somewhere in the world. This means that he should be trained in searching this type of information. And finally in those cases where no design method is available, our engineer has to perform his own research (or write an research assignment to be executed by a specialized institute). In some cases this is necessary. But in $90 \%$ (or more) of the design cases, this is not relevant.

Having made a (far from complete) overview of academic coastal education in the world, the conclusion is that in those universities where coastal engineering is presented, it is usually a specialisation of civil (or hydraulic) engineering, offering only a few graduate courses really in coastal engineering. The most common situation is that in the final year, the hydraulic engineer can follow a few lectures in specialised coastal engineering topics, followed by a thesis on the subject. In the very few more specialized universities, in the last year of the programme more coastal topics are presented and the thesis is usually linked to the current faculty research programme of the institute. Hardly anywhere an M.Sc.- 
programme is offered, focusing on coastal engineering only, and give the student the possibility to gather real engineering (design) qualifications.

For a practising engineer, working in a multi-disciplinary team, it is vital to know the physical processes instead of only knowing the mathematical approximation of these processes ${ }^{2}$. In education this point is often underexposed. Especially in the education of engineers from developing countries attention has to be paid to the education of the design (type 3) engineers, see VERHAGEN [1995].

\section{GENERAL REQUIREMENTS FOR COASTAL ENGINEERS}

In our institute we have 39 years of experience in giving coastal engineering courses to participants from countries which do not have a tradition in training of coastal engineers. The conclusion is that there is a great need for engineers who are able to plan, design, construct, maintain and manage coastal structures. The need for engineers with abilities to design coastal structures of a very complicated technical nature is much less. Although the interest of both universities and politicians is often different, maintenance and management of coastal structures are important and costly matters. It is important to include maintenance and management aspects already in the design phase, see VERHAGEN AND YAP [1992]. Based on our experience we came to the conclusion that for the design engineers the following requirements are the most important ones:

- good understanding of the basics of the physical processes;

- insight in the effect of reliability of data, used in the design processes (also including the ability to design a construction as less as sensitive to uncertain input data);

- select the appropriate tools for analyzing the problem and designing a solution;

- develop capabilities to organise the design work in a straightforward way, given the limited resources available;

- develop to ability to cooperate with specialists from other disciplines in a interdisciplinary coastal zone management project;

- develop capabilities to come to practical solutions given the local constraints;

- the ability to formulate research assignments.

Because, according to our experience, the engineering qualities and the design and management skills are the most important requirements for coastal (design) engineers, we started to define the required qualities and skills, instead of a list of subjects to be taught. For the engineering qualities and the design and management skills, we have worked this out into the following general objectives:

A clear example can be found in wave-mechanics. Often teaching starts with the dispersion equation for gravity surface waves (in fact a mathematical model description). And then, for example, refraction is explained by combining the dispersion equation with the continuity of wave crests in order to get a formula for the ray curvature. Usually this is not very clarifying for students with an engineering attitude. 
Engineering qualities:

The coastal engineer:

- has a good quality engineering attitude, i.e. he is able to analyze practical problems in his profession, is able to generate solutions and is able to implement the engineering solutions in a sound way; doing this the engineer is knowledgable with respect to his profession, but also aware of the surroundings and the environments of the project, and is able to organize the solving the problem and implementing the solution in a interdisciplinary environment.

- has some knowledge of technical and scientific developments in fields adjacent to his own field and is able to communicate with experts in those fields; examples for coastal engineers are: river engineering aspects, inland navigation, merchant shipping, port management, information technology, environmental sciences.

- has knowledge of modern design methodologies, like the probabilistic approach and the policy analysis approach to select alternatives, and is able to apply them.

- is aware of the fact that hydraulic engineering structures always have a large impact on the environment in its widest meaning; the engineer has to be able to make an inventory the impacts of his work with the aid of specialists in environmental sciences and to execute an environmental impact assessment.

- is able to define the required input data for his problem; he is able to judge the required accuracy of the data; he is able to compose an adequate dataset from an ambiguous dataset.

- is able to search in international literature and databases for relevant design methodologies.

\section{design skills}

The coastal engineer is able to:

- analyze coastal (erosion) problems, to generate alternative coastal protection methods (including "soft" methods), to select a protection method, to design the protection and to supervise the construction of the protection.

- protect low-lying coastal areas from flooding by means of the construction of dikes and revetments; he is able to determine the functional requirements of the protection, to generate alternative flood protection methods, to select a protection method, to design the protection and to supervise the construction of the protection.

- evaluate the necessity and to design closure dams, causeways, etc. in a coastal, tidal environment; he is able to determine the functional requirements of the dam, to generate alternative lay-outs and construction methods, to select an alternative, to design it and to supervise the construction of the dam.

- design the entrance to a harbour, i.e. the design of the access-channel and the design of the breakwater; he is able to determine the design boundary conditions, to generate alternative solutions, make a selection, make the detailed design and supervise the construction.

- design mooring facilities, both at offshore jetties as along quay-walls, he is able to develop and select alternatives and is able to design the structure; he is able to specify the boundary conditions for quay-wall and jetty construction; he is able to design a jetty and a quay-wall.

- design earth structures and foundations in the coastal zone (dikes, sheetpiles, soil improvement techniques), the coastal engineer has a workable knowledge of pile foundations. 
managerial skills

The coastal engineer:

- is able to organize and cooperate in a multi-disciplinary group to set-up and implement an integrated coastal zone management plan.

- has specific knowledge of construction methods specific for coastal engineering, i.e. wet and dry earth moving; related to dredging he has to be able to define the working method, to know the possibilities of the industry, to prepare terms-of-reference and contract and price estimate; he is able to select the contractor and to supervise the work.

- is able in case of environmental emergencies in the coastal zone (oil-spills, hurricanes, etc) to organize the appropriate actions to mitigate the impact.

- has some knowledge regarding the organization of the profession, the international institutions, the organization of large contractors and consultants.

Having defined these more general qualities and skills, the next step is to define the required knowledge for individual subjects, like "design of breakwaters" or "short waves". Only those aspects of the several subjects should be taught, when they contribute to the general qualities and skills, as defined above. If one neglects this point, the result is usually a programme which consists of a set of hobbies of the teachers. Because of the limited scope of this paper, this step will not be worked out.

\section{ATTAINMENT TARGETS}

Of course these objectives, but also a list of topics within a series of lectures gives no information regarding the level, depth or orientation of the subject. Often one sees in curricula of universities descriptions like:

\section{Short waves}

linear and non-linear regular gravity waves, wave properties and transformation in shallow water, forecasting and hindcasting of waves.

In fact, such a description gives not very much information. For example, after having followed this course, is the student able to derive refraction equations, is he able to make a refraction calculation by hand, is he able to interpret the results of a refraction calculation by a computer programme, is he able to define whether a refraction calculation is necessary or not, and if yes, what are the input variables ???

Therefore it is more appropriate to describe as detailed as possible the attainment targets a student has to meet in order to get his diploma. For "refraction", such targets could be described as follows:

- Know the phenomenon of refraction, be able to calculate refraction in case of parallel depth contours, using Snell's law, be able to determine refraction in a qualitative way in case of non-parallel depth contours, know the advantages and problems of rayrefraction programs, be able to interpret two-dimensional wave penetration programs.

Attainment targets can be worked out for all course objectives, mentioned above. As an example the attainment targets for the design capabilities are given below: 


\section{Attainment targets for design capabilities}

- be able to translate a vague (political) question into exact requirements and formulate them in terms-of-reference for a study to be performed

- be able to analyze the problem on main aspects and distinguish between essentials and matter of secondary importance

- to be able to analyze the functional requirement of the construction needed, in order to determine design criteria

- be able to collect data for a (real world) project from the general available data sources (like libraries, information retrieval systems, already existing consultancy reports)

- be able to analyze the above mentioned data and to be able to use them in order to come to a complete, relevant and unambiguous set of boundary conditions (including the reliability of the given figures)

- be able to determine scenarios to describe unknown future effects

- be able to determine alternative designs

- be able to make global designs of the alternatives, in order to make a selection; be able to make a choice between the various available computational and design methods; be able to apply these methods

- evaluate the designs on at least the following aspects

- costs

- maintenance cost

- environmental acceptance - robustness of the design

- social acceptance - executionability

- be able to read technical drawings, to be aware of the effects of distorted scales (especially in coastal profiles)

- be able to make a bill of quantities given the design drawings

- be able to make a set-up for an Environmental Impact Assessment for the design

- be able to write a systematic report on the design process followed

- be able to write readable well-structured reports, with clear set-up, and with a good quality lay-out.

- be able to organize the design work, define various subtasks and have these subtasks executed by various group members

- be able to make a time planning for a design work, and be able to produce the design report; i.e. to deliver the report (1) in time, (2) with the subjects as determined in the original plan, (3) with the required quality; the sequence of these points is important

- be able to present the results of a study or design work orally in a short period (10-30 minutes) for various types of audiences (such as technical experts, decision makers, financial experts); be able to make good quality overhead sheets (both from a viewpoint of contents as lay-out)

- be able to gather additional skills and knowledge on a rather specialistic field (not treated in detail in the teaching programme) in order to solve the design problem.

\section{THE MASTER DEGREE}

The engineering study is usually completed with a Master degree. Unfortunately there is not really a world-wide standard for a master degree. Especially for students from developing countries this is a real problem. For most of them their career depends completely on the fact if they have paper indicating a Master degree, and not on their knowledge or skills. So in fact it is for them very unattractive to follow a high quality course. Usually these courses are long (and therefore costly), with a high risk of failure for the candidate; so why not go to an easy course ? This strong focus on "paper" degrees is a 
clear problem in the developing world. But on the other hand, for an outsider it is indeed difficult to assess the quality of a diploma. Therefore the detailed described attainment targets can be very useful. In fact, by issuing the diploma, we guarantee that the candidate has reached all the described attainment targets, so a future employer can easily see what is the knowledge and skill of the degree-holder.

There is a variety of Master titles, a taught masters, a master by thesis, a master of engineering, a master of science, etc. In our institute we provide two types, a Taught Masters and a Master of Science. The first is given to a student who has followed the complete (2000 study hours) program, has done all exercises sufficiently and who has passed all examinations. Students with sufficient high marks for the Taught Masters programme are academically admitted to the Master of Science programme, which consists of an additional individual assignment of approx. 1000 hours. This individual assignment can be a research work, but can also be a design work. Of course not all design work automatically has sufficient level for M.Sc. We use the following list of requirements for a subject for designwork at M.Sc.-level

- It has to be a complex problem, i.e.:

- The boundary conditions are ill-defined

- The criteria are not clear on beforehand

- There are several, complex scenarios.

- The technical solution is complicated, this means that it is not possible to apply straightforward existing design formulas.

- It is not possible to determine the best alternative by a simple (one-dimensional) computation.

- The problem has to be realistic and relevant, preferably for the home-country of the participant.

\section{CONCLUSIONS}

Because of the focus on research in most universities of the world, the training and education of design engineers is somewhat problematic. Many design engineers have been trained as researchers. In future there is a need for trained designers with understanding of coastal processes, the ability to design in a flexible way coastal "constructions" and able to communicate with others. Training programs can be improved considerably by defining the attainment targets which have to met by the students at the end of their education, and not only by defining the subjects to be dealt with in the curriculum.

\section{REFERENCES}

AввотT, M.B. [1994] Hydroinformatics: A Copernican revolution in hydraulics; J. of Hydraulic Research, vol 32, extra Issue, pp 3-13

HILDEBRANDO DE A. GÓES FILHO [1995] Profile of the new coastal and port engineering technician at the end of the 20th century; Invited Paper, Copedec IV, Rio de Janeiro, Brazil

Kobus, H., Plate, E., HSIEH, Wen-Shen, SzÖllöSI-NAGI, A. [1994] Education of Hydraulic Engineers; J. of Hydraulic Research, vol32, nr2, pp 163-181

SMITH, A.W.S. [1994] The coastal engineering literature and the field engineer; J. of Coastal Research, vol 10, no2, pp iii-viii

VERHAGEN, H.J. [1995] The requirements for Coastal Engineers in Integrated Coastal Zone Management; Copedec IV, Rio de Janeiro, Brazil

VERHAGEN, H.J. \& YAP, J. [1992] Coastal Zone Management with relation to Low Investment Solutions; proceedings Second seminar on Ports and Inland Waterways in Devel- 
oping Countries, PIANC-PCDC; Surabaya 1992 